IZA DP No. 7278

\title{
A Theoretical Model of the Chinese Labor Market
}

Gary Fields

Yang Song

March 2013 


\title{
A Theoretical Model of the Chinese Labor Market
}

\author{
Gary Fields \\ Cornell University \\ and IZA \\ Yang Song \\ Renmin University of China
}

\author{
Discussion Paper No. 7278 \\ March 2013
}

\author{
IZA \\ P.O. Box 7240 \\ 53072 Bonn \\ Germany \\ Phone: +49-228-3894-0 \\ Fax: +49-228-3894-180 \\ E-mail: iza@iza.org
}

Any opinions expressed here are those of the author(s) and not those of IZA. Research published in this series may include views on policy, but the institute itself takes no institutional policy positions. The IZA research network is committed to the IZA Guiding Principles of Research Integrity.

The Institute for the Study of Labor (IZA) in Bonn is a local and virtual international research center and a place of communication between science, politics and business. IZA is an independent nonprofit organization supported by Deutsche Post Foundation. The center is associated with the University of Bonn and offers a stimulating research environment through its international network, workshops and conferences, data service, project support, research visits and doctoral program. IZA engages in (i) original and internationally competitive research in all fields of labor economics, (ii) development of policy concepts, and (iii) dissemination of research results and concepts to the interested public.

IZA Discussion Papers often represent preliminary work and are circulated to encourage discussion. Citation of such a paper should account for its provisional character. A revised version may be available directly from the author. 


\section{ABSTRACT}

\section{A Theoretical Model of the Chinese Labor Market}

This paper constructs a theoretical labor market model for China, and utilizes the model to examine the effects of various labor market policies on economic well-being. Two key features of the model are a segmented labor market involving three sectors - state-owned enterprises, private enterprises, and agriculture - and China's unique household registration system (hukou). The major existing theoretical models of employment and development - the Lewis model, the integrated labor market model, the Harris-Todaro model, and various segmented labor market models - stylize different developing countries' labor markets in other ways but do not include these two key features. The paper first formulates the equations of the model, then obtains a closed form solution given initial conditions, and then deduces the labor market and welfare consequences of several policy interventions, which include promoting rural development, reducing the cost-of-living in urban areas for rural hukou holders, and offering some rural workers the chance to convert from rural to urban hukou status. These policy interventions are analyzed using two alternative welfare criteria: first-order stochastic dominance and an abbreviated social welfare function. Using both social welfare criteria, it is shown that the rural development policy is unambiguously welfareimproving, while the other two policies have ambiguous effects on social welfare. None of these policies is unambiguously welfare-decreasing.

JEL Classification: $\quad$ I3, J2, O1, O53

Keywords: labor markets, employment, welfare economics, China, hukou

Corresponding author:

Yang Song

School of Economics

Renmin University of China

59 Zhongguancun Avenue

Beijing, 100872

China

E-mail: ys337@cornell.edu 


\section{Introduction}

China’s labor market was freed up greatly beginning in 1978 as part of the larger economic reforms introduced at that time. Previously, there had been no labor market; all workers had been assigned to jobs by local governments, schools, or communities. Since the 1990s, workers have been largely free to search for better jobs, and employers have been largely free to hire and fire workers as desired. Moreover, the past twenty years witnessed also a steady urbanization process in China featuring an increasing flow of labor from rural areas to cities as regulations on rural-urban migration have been slowly relaxed.

However, the current Chinese labor market has two main features that are not only different from other countries’ labor markets, but also different from what it used to be two decades ago. First, the Chinese labor market is segmented, involving state-owned enterprises (SOE), private enterprises, and agriculture sector. The three employment sectors pay different wages to comparable workers, with the SOE sector on top, private sector in middle, and agriculture sector at bottom. Furthermore, high-wage jobs are rationed meaning that there are qualified individuals who would like to find a high-wage job but cannot find a job there due to the lack of good jobs in this sector.

The second core feature of the current Chinese labor market is the household registration system (hukou). The hukou system requires that each person born in China be assigned either rural hukou or urban hukou in a given location. Up until the 1990s, rural hukou holders had not been allowed to migrate to cities and work there. These restrictions on labor mobility within China regulated by the hukou system have been relaxed significantly in the past two decades. Chinese workers are now free to move and work in any place within China. Although the hukou system no longer prohibits Chinese workers from migrating to places different from where they were born, it still plays a large role in the current Chinese labor market. Workers with urban and rural hukou are treated differently in the urban labor market, 
face different costs of living in cities, and have different access to government-provided public service in the urban area.

Based on a segmented labor market and China's unique hukou system, the present paper constructs a theoretical labor market model for China and utilizes the model to examine the effects of various labor market policies on social welfare by two alternative welfare criteria: the first-order stochastic dominance approach and the abbreviated social welfare function approach. As Fields (2007) pointed out, good policy work requires sound theoretical foundations. Without developing a theoretical model of the current Chinese labor market, we may not be able to evaluate how a proposed policy would affect people's economic well-being, since a policy implemented in one sector or targeted on one group may generate unexpected outcomes on another economic sector or other groups.

Building on empirical features of the Chinese labor market detailed in Song (2013), the theoretical model constructed in this paper has two geographically distinct areas (urban and rural), three economic sectors (SOE, private, and agriculture), and two types of workers distinguished by the hukou status (urban and rural hukou). The three sectors' labor markets operate in three different ways. The SOE sector pays the highest wage, hiring is restricted to a subset of the available labor force, and SOEs practice both wage and hiring discrimination against rural hukou holders. The private sector labor market pays a market-clearing wage which is lower than the wage in the SOE labor market; private sector employers exhibit no labor market discrimination. The agriculture sector located in the rural area pays an even lower wage; this sector employs all workers who supply their labor there.

In comparison with previous theoretical models of the Chinese labor market, our model has more sectors, incorporates the role of the current hukou system, has more fully-specified labor markets and inter-market linkages, obtains a closed form solution before modeling any policy interventions, and works out the welfare consequences of the various possible policy interventions more fully. 
Specifically, we conduct three policy experiments using the model, including promoting rural development, reducing the cost-of-living in urban areas for rural hukou holders, and offering some rural workers the chance to convert from rural to urban hukou status. The main policy results are that the rural development policy is unambiguously welfare-improving, while the other two policies have ambiguous effects on social welfare using either welfare criterion. No policy among the three alternatives unambiguously reduces economic well-being.

The remainder of the paper proceeds as follows. Section 2 provides a brief review of existing labor market models and demonstrates the contributions of this paper to the literature. Section 3 elaborates the features of our theoretical model based on previous empirical research. Our theoretical model is presented in Section 4. Section 5 conducts three policy experiments and examines their effects on income distribution using two alternative policy evaluation criteria including first-order welfare dominance approach and abbreviated social welfare function. Section 6 provides concluding remarks and future research directions.

\section{Our contributions to the literature}

The majority of previous research on analyzing the Chinese labor market was based on the Nobel Prize-winning dualistic labor market model formulated by Lewis (1954). The Lewis model contains two economic sectors - including the high-wage capitalist sector and the low-wage subsistence sector - and no unemployment. There are two phases in the Lewis model. In Phase 1, the capitalist sector faces an unlimited supply of labor due to the wage gap between it and the subsistence sector, so employers in the capitalist sector do not need to raise wages to attract additional labor. Thus, the wage in the capitalist sector remains constant in the first stage. Finally, a turning point is reached once the supply of labor to the capitalist sector is no longer unlimited in the sense that capitalist sector employers must raise wages in order to attract additional workers. In this second phase, wages would increase in the two sectors at the same rate as economic growth proceeds. In summary, the first phase of the 
Lewis model features a constant wage in the capitalist sector and rising wage in the subsistence sector, while the second phase is characterized by wage increases in the two sectors at the same rate.

Although there are numerous studies on the debate about whether China has passed the Lewis turning point (Knight et al., 2011; Cai, 2010; Song and Zhang, 2010; Lu and Jiang, 2008), we claim that the Lewis model doesn't fit China because the Chinese reality does not hold either in Phase 1 or in Phase 2 of the Lewis model. Like other researchers on China, we use urban areas and rural areas as proxies for Lewis's capitalist sector and subsistence sector respectively. Empirically, China has experienced neither a period in which the urban wage remains constant while the rural wage rises (Phase 1 of the Lewis model), nor a period in which rural and urban wages are equal and increase at the same rate (Phase 2 of the Lewis model). In China, urban and rural wages have both been increasing, but urban wages have grown much faster than rural wages. Accordingly, the whole discussion about whether China has passed or not passed the Lewis turning point is not well specified.

Another seminal segmented labor market model is the Harris-Todaro model (Harris and Todaro, 1970). The model again has two sectors but allows for open unemployment. The two sectors of the economy are an urban sector and an agricultural sector. In their model, the urban sector wage is set institutionally above the market-clearing wage and is assumed to be above the agriculture wage. The above-market-clearing wage in urban areas results in urban unemployment. Migration in this model is driven by the difference in the expected wages between urban and rural sectors. Equilibrium between urban and rural areas is achieved when the expected wages between rural and urban search strategies are equal to each other. This model can explain the phenomenon of open unemployment in the urban area, and has been employed to analyze the effects of various public policies, such as urban employment creation and rural development. The main problems with applying the Harris-Todaro model to contemporary China are that it lacks a sufficient number of sectors and it posits unemployment in urban but not rural areas, which does not fit the Chinese reality. 
To date, only a few researchers have attempted to construct models particularly for the Chinese labor market. Among these, the most full-specified model was that of Meng (2000). She developed a three-sector segmented labor market model with features of the hukou system. The three sectors include an agricultural sector, an urban high-wage sector, and an urban low-wage sector. The model assumes that urban hukou holders only take jobs in the urban high-wage sector, and low-wage jobs in urban areas are filled exclusively by rural hukou holders. That is, the urban labor market is fully segregated in that urban hukou holders only work in the high-wage sector, while migrants with rural hukou in the city only work in the low-wage sector. This assumption was valid in the 1990s when city governments implemented discriminatory policies to prohibit rural migrants in the city from working in the high-wage sector or taking high-wage jobs. However, the current Chinese reality is different, since governmental regulations against rural migrants working in certain industries and occupations in cities were eliminated in 2004 (Song, 2013). In summary, although Meng's model was an accurate stylization of China's labor market in the 1990s, it does not characterize the current workings of China's segmented labor market.

Moving beyond Meng's model and other segmented labor market models, the present paper establishes a rigorous theoretical model of the current Chinese labor market. Our model makes three contributions to the literature.

First, the model contains three economic sectors, provides more realistic stylizations of the workings of the labor markets in each sector, and contains more reasonable specifications of the linkages between sectors. For instance, the model reflects the current feature that both urban and rural hukou holders are working in each of the two urban sectors, which was not allowed in Meng's model.

Second, the model constructed in this paper specifies the workings of the current hukou system in China's labor market. Based on some very recent empirical papers on the Chinese 
hukou system, the model captures the stylized fact that workers with different hukou are treated differently in the urban labor market, face different costs of living in cities, and have different access to government-provided public service in the urban area. Almost all of the previous literature on modeling the Chinese labor market only claimed that the hukou system is a major institutional restriction on labor mobility, but did not analyze how it actually works. The hukou system was similar to a black box which previous researchers had never explored for the purpose of modeling the Chinese labor market.

Third, this paper utilizes the model to analyze the welfare consequences of various labor market policies using two well-specified welfare evaluation criteria: first-order stochastic dominance approach and an abbreviated social welfare function. Some researchers have tried to conduct policy analysis on the Chinese labor market (Hertal and Zhai, 2006; Ito, 2008). However, these studies either explicitly or implicitly use the magnitude of rural-to-urban migration as a policy evaluation criterion. They essentially hold the opinion that policies which would promote rural-to-urban migration are desirable and welfare-improving. We claim that this criterion is not appropriate because there is no economic or moral reason to simply judge whether migration is good or not for people's economic well-being in a country. In contrast, this present paper employs well-defined welfare criteria to analyze the effects of labor market policies. The unprecedented result of this paper will give Chinese policy makers crucial guidance about how to design labor market policy in order to improve social welfare.

To recapitulate, in comparison with the previous literature, we construct a theoretical labor market model for current China containing more fully-specified labor markets and inter-market linkages and incorporating the role of the current hukou system, obtain a closed form solution under existing conditions, model a number of policy interventions, and work out the welfare consequences of the various possible policy interventions.

\section{Features of the model}

\subsection{Two locations: urban and rural area}


The model has two locations: an urban area and a rural area. The urban area can be thought of as a city in coastal China such as Shanghai or Beijing and the rural area as inland China. As is known, the coastal part of China is richer than inland China. In fact, the majority of rural-to-urban migrants are located in coastal cities to pursue higher income compared to central and western China. Thus, the model reflects the most typical migration pattern in current China, from inland rural area to coastal urban area. In the model, there is no differentiation within urban and rural areas.

\subsection{Three segmented employment sectors}

There are three sectors in total in the whole economy, including state-owned enterprises (SOEs), private firms, and the agricultural sector. The SOE and private sectors are located in the urban area, and the agricultural sector is in the rural area. In current China, nearly $50 \%$ of the total labor force is working in urban areas and 50\% in rural areas. Within rural areas, more than half of the labor force is still working in the agricultural sector, and the rest is working in the rural non-agricultural sector. Within the urban labor force, more than three quarters are working in the private sector (Song, 2013).

The various sectors differ from one another in two major respects: wages and job search opportunities. It is documented in the empirical literature that for comparable workers, the SOE sector pays the highest wages, with the private sector in the middle and agriculture at the bottom (Song and Li, 2010).

We turn now to detailed specifications of the various sectors' labor markets. 


\subsubsection{SOE sector labor market}

The wages paid to workers with each hukou in the SOE sector are set exogenously by the government for political reasons and higher than the market-clearing levels as well as wages in any other sectors. As a result, all workers want to have a job in the SOE sector, because it pays higher wages than any place else. However, since the SOE sector labor market does not clear, it does not hire all of the people who want to work there.

SOE sector employers discriminate against rural hukou holders. This discrimination takes the form of both wage and hiring discrimination. Song (2013) showed that for observationally-equivalent workers, urban hukou holders earn about $50 \%$ more than rural hukou holders in the SOE sector ("wage discrimination”). In addition, comparable workers with urban hukou are 35 percentage points more likely to be hired in the SOE sector than are rural hukou holders ("hiring discrimination”). Since the SOE sector is commonly thought of as part of government, the political power helps the SOE sector afford the discrimination against workers with rural hukou.

Foreign-owned enterprises are excluded from the model. It has been shown that the wage level in foreign-invested enterprises is similar to that in the state-owned enterprises and also higher than the market-clearing wage (Chen et al., 2005). Therefore, our model can be understood as including foreign-invested enterprises as part of the SOE sector.

\subsubsection{Private sector labor market}

The urban private sector labor market clears for both rural and urban hukou holders, and therefore all the labor supplied to that sector is demanded. Several authors have claimed that the private sector wage in China is largely market-determined, and institutional interventions such as minimum wage or labor unions play a small role in wage-setting mechanism (e.g., Dong and $\mathrm{Xu}, 2009)$. 
In our model, all workers located in the urban area who do not get employed in the SOE sector supply their labor to the private sector. Because the private sector pays a market-clearing wage, anybody who does not get a SOE job is able to obtain a job in the private sector and work there, regardless of this person's hukou status. Thus, there is no open unemployment in the urban area.

Private sector employers are assumed not to be discriminatory. The average wage differential between urban and rural hukou holders is very small in private firms, and furthermore, a large proportion of the wage differential can be explained by different human capital between the two groups of workers (Song, 2013).

The model does not have an urban self-employment sector for the following two reasons. One is that self-employment in urban China only accounts for a small proportion of the total urban labor force. About 20 percent of rural hukou holders and 10 percent of urban hukou holders in cities are self-employed (Giulietti et al., 2012). Second, the wage differential between workers in private firms and the self-employed is very small after controlling for characteristics (Giulietti et al., 2012). Therefore, self-employment can be thought as part of the private sector in the model.

\subsubsection{Agricultural sector labor market}

The agricultural labor market is characterized by self-employment. In rural China, a person located in the rural area is automatically allocated a piece of land. Farmers cultivate crops on their own land and sell the products. Feng (2008) said that the land rental market is still in its infancy. Thus, self-employment is still dominant in poor rural areas. Furthermore, we assume that all agricultural sector workers earn the same self-employment wage as each other.

In addition, following the assumption by Fields (1975) and Stiglitz (1982), our model assumes that the wage in the rural agriculture sector is invariant with respect to the agricultural labor force. This assumption makes some sense because in the context of 
self-employment, the marginal agricultural worker can produce essentially the same amount of additional product as can agricultural workers already there.

We exclude the rural non-agricultural sector from this model, since such rural non-agricultural enterprises as exist are mainly concentrated in rural areas of coastal China (Ash, 2010). Again, the model only consists of a single rural area in inland region, and a single urban area in coastal region of China.

\subsection{Inter-market linkages}

Any worker in this economy has two possible search strategies, either going to the urban area and searching for jobs there or going to the rural area and accepting the agricultural wage. Workers with urban hukou have one pair of payoffs for urban versus rural search, and workers with rural hukou have a different pair of payoffs for urban versus rural search.

This model does not allow for on-the-job search, as was modeled by Fields (1975). That is, following Harris and Todaro (1970), any person who wants to work in the city has to be physically located in the urban area and search for urban jobs. People who adopt the rural search strategy can only accept the agricultural wage and have no chance of being hired for an urban job.

Workers allocate themselves among two search strategies in order to maximize expected discretionary income by choice of search strategy. The assumption of expected wage equalization in the equilibrium was made by most of previous seminal models (Harris and Todaro, 1970; Fields, 1975). The terminology of expected "discretionary income” differs from expected wage in that it takes into account other benefits and costs associated with each search strategy. The benefit may include various government-provided welfare benefits, and the cost refers to the cost of living in the destination. In the equilibrium, workers have equal expected discretionary income among different search strategies. 


\subsection{The role of hukou in the labor market}

All workers in this model have either urban or rural hukou, with which they are endowed and cannot change. Currently, the most important determinant of a person's hukou type is the hukou type of the parents when the person was born (Chan, 2010). One’s hukou status remains unchanged no matter where the individual is physically located, unless he or she goes through a formal process of hukou conversion. However, many large cities in coastal China, which are the main destinations of rural-to-urban migrants, put up the most stringent conditions for granting local urban hukou. The present hukou conversion policy in big cities is almost totally geared towards the super rich and the highly educated and is irrelevant to most rural-to-urban migrants. The strict requirements of hukou conversion are clearly beyond their reach. Therefore, in this paper, we assume that people cannot change their hukou status unless the government permits some of them to.

Although people are free to move between urban and rural areas within China, rural hukou holders face two major disadvantages in the cities. First, they have limited access to public services and welfare benefits provided by city governments. Compared to urban hukou holders, workers with rural hukou in urban areas have much less access to a variety of public service and welfare programs such as medicare, housing subsidies, social security coverage, and so on. In current China, most of public service and welfare benefits are attached to a person's hukou status rather than physical location. Rural hukou holders can physically move to a new place but still be permanently barred from access to local services and welfare programs. Second, even when rural hukou holders do have access to urban services and programs, they have to pay a higher cost of living in the city than urban hukou holders do. For instance, the children of rural migrants have to pay a very high fee to attend public schools in the destination city (Chen and Yang, 2010). These differences in access and costs, coupled with wage differentials, are what in this paper we term "differences in discretionary income.” 
Additionally, our model assumes that workers with urban hukou are inherently more productive than rural hukou holders for urban jobs, because urban hukou holders on average have more human capital than urban hukou holders do. The rationale of this feature is that people in rural China receive less and relatively poorer-quality education than do people in urban areas (Song, 2012). We model these productivity differences as differences in efficiency units of labor, whereby a given rural hukou holder possesses fewer efficiency units than a given urban hukou holder.

Finally, as discussed previously, rural hukou holders face wage and hiring discrimination in the urban SOE sector. The wage discrimination implies that rural hukou holders' efficiency units of labor are rewarded less than equally productive efficiency units of labor for urban hukou holders. Besides, rural hukou holders also face hiring discrimination in the urban SOE sector meaning that they get hired with reduced probability compared to urban hukou holders.

\subsection{No unemployment}

There is no unemployment in the whole economy of the model. In rural China, the Household Responsibility System (HRS) guarantees that everybody has his or her share of land, so it is a reasonable assumption that rural unemployment is as low as negligible since workers can easily obtain a piece of land to work. In slack agricultural seasons, many workers choose part-time job in urban areas. Even for people staying in rural areas during the slack seasons, if they are not actively searching for jobs, they would not be counted as unemployed. The only effect of non-working in slack seasons is a reduction in labor force participation rate, but not an increase in rural unemployment. Thus, it makes sense to claim that rural unemployment does not exist.

On the other hand, as observed in the empirical literature, urban areas in coastal China are facing a labor shortage, rather than a Harris-Todaro-type labor surplus (Chan, 2010). Therefore, in our model, there is no urban unemployment either. 


\section{Model specification}

The previous section summarized the main features of our model. In this section, we provide the specific mathematical equations incorporating these features and obtain closed form solutions for each of the employment and wage levels.

The economy in this model consists of a large number of risk-neutral individuals and three economic sectors. There are two sectors in the urban area, the SOE and private sector, and only one sector in the rural area, which is the agricultural sector. Firms within each sector are identical and have the same production functions.

Any person in this economy has one of the two hukou statuses, either rural or urban hukou. Let $L$ be the total number of workers in this economy. Among these workers, there are $L^{U}$ workers with urban hukou, and $L^{R}$ workers with rural hukou. These two numbers are set exogenously by the government and will keep unchanged in the following model. The labor endowment equation is specified in equation (1):

$$
L^{U}+L^{R}=L .
$$

As discussed above, workers with urban hukou have more human capital and thus are inherently more productive than rural hukou holders for urban jobs. Following the convention from previous literature, we use efficiency units of labor to reflect this productivity differential (Saint-Paul, 1994; Razin and Sadka, 1995). Assume that a worker with urban hukou is endowed with one efficiency unit of labor, regardless of whether this person works in the city or in the rural area. In contrast, a rural hukou holder can provide only $\beta<1$ efficiency units of labor if he works in the city, and one efficiency unit of labor if he works in the rural area for agricultural work. That is, workers with different hukou are inherently 
equally productive for agriculture work in the rural area, but have different productivity for urban jobs. ${ }^{1}$ Efficiency units of labor are the only factor of production in each sector.

\subsection{SOE sector labor market}

The wages paid to workers with each hukou in the SOE sector are set exogenously by the government for political reasons and higher than the market-clearing wages. Let $W_{S}^{U}$ and $W_{S}^{R}$ stand for the wages for urban and rural hukou holders in the SOE sector, respectively. The superscript denotes the hukou type, and the subscript refers to the economic sector. Accordingly, the wages per worker with each hukou type in the SOE sector are exogenously determined as follows.

$$
\begin{aligned}
& W_{S}^{U}=\bar{W}_{S}^{U} . \\
& W_{S}^{R}=\bar{W}_{S}^{R} .
\end{aligned}
$$

Taking wages of each type of workers as given, firms in the SOE sector decide how many workers with each hukou status to hire. Firms in the SOE sector discriminate against rural hukou holders, practicing both wage and hiring discrimination. Specifically, wage discrimination refers to the fact that the SOE sector pays higher wages to each efficiency unit of labor with urban hukou than each efficiency unit of labor with rural hukou. Since each urban hukou holder has one efficiency unit of labor for the job in the SOE sector, and a rural hukou holder has only $\beta<1$ efficiency units of labor, wage discrimination against rural hukou holders implies:

$$
W_{S}^{U}>\frac{W_{S}^{R}}{\beta}
$$

\footnotetext{
1 A more reasonable assumption would be that rural hukou holders are more productive than urban hukou holders for
} rural agriculture jobs. However, this assumption would not affect the results of this paper. 
The left hand side of the equation above denotes the wage for one efficiency unit of labor with urban hukou, while the right hand side is equal to the wage for one efficiency unit of labor with rural hukou. Equation (4) implies that the wage differential between workers with urban and rural hukou in the SOE sector is not only caused by the productivity differential, but also by the different treatment to the equally productive efficiency units of urban and rural labor in the SOE sector.

Moreover, rural hukou holders also face hiring discrimination in state-owned enterprises in that SOE sector employers maximize utility, which is a function of profits and also disutility of hiring rural hukou holders. This specification is similar to the framework proposed by Becker’s (1971) model of employer discrimination. In Becker’s original model, the disutility is linear in the number of discriminated workers. However, several papers have argued that this linear specification can either lead to full segregation or indeterminacy of the demand functions (Prieto-Rodriguez et al., 2008; Hellerstein et al., 2002; Neumark, 1988). They claimed that a more reasonable assumption is that the total disutility is a convex function in the number of discriminated workers.

We follow the convention in the literature and assume that the marginal disutility is increasing as more and more rural hukou holders enter the SOE sector. For analytical convenience, we employ a simple quadratic form for the disutility of hiring rural hukou holders. Let $E_{S}^{U}$ and $E_{S}^{R}$ denote the total number of workers with urban and rural hukou demanded by firms in the SOE sector, respectively. Firms in the SOE sector have the same discrimination coefficients denoted by $d$, and maximize the utility function as follows by choosing how many workers of each hukou type to hire.

$$
\operatorname{Max} U=f_{S}\left(E_{S}^{U}+\beta E_{S}^{R}\right)-W_{S}^{U} E_{S}^{U}-W_{S}^{R} E_{S}^{R}-d\left(E_{S}^{R}\right)^{2} .
$$


The price of the output in the SOE sector is normalized to $1 . f($.$) is a typical$ production function, with $\mathrm{f}^{\prime}>0$, and $\mathrm{f}^{\prime \prime}<0$. In order to obtain closed form solutions to the maximization problem above, we need to specify the production function in the SOE sector. For mathematical tractability, we choose a left half parabola as the functional form for the production function. For our purposes, the quadratic specification on the production function has at least two advantages. First, it is a strictly increasing and concave function, which satisfies the conditions for a typical neo-classical production function. Second, it is sufficiently simple to allow for the derivation of closed form solutions. Thus, we have

$$
\begin{gathered}
E_{S}=E_{S}^{U}+\beta E_{S}^{R} . \\
f_{S}=-\left(E_{S}-a\right)^{2}+b, \mathrm{a}>E_{S}^{M A X}>0 .
\end{gathered}
$$

$E_{S}$ denotes the number of efficiency units of labor demanded by the SOE sector, and consists of two terms as shown above. Given this production function, with $a$ and $b$ being positive parameters, we can solve for the utility maximization problem specified in equation (5). The following two equations stand for the solutions to the number of rural and urban hukou holders demanded in the SOE sector, respectively.

$$
\begin{gathered}
E_{S}^{R^{*}}=\frac{\beta \bar{W}_{S}^{U}-\bar{W}_{S}^{R}}{2 d}, \\
E_{S}^{U^{*}}=a-\frac{1}{2} \bar{W}_{S}^{U}-\beta \frac{\beta \bar{W}_{S}^{U}-\bar{W}_{S}^{R}}{2 d} .
\end{gathered}
$$

\subsection{Private sector labor market}

Private sector employers are not discriminatory, so each efficiency unit of labor is rewarded the same in the private sector regardless of the holder's hukou status. Let the wage per efficiency unit of labor in the private sector be equal to $W_{N S}$. We use "NS" (non-SOE) to 
denote the private sector from now on, reserving "P” for probabilities in later sections. Since efficiency units of labor are the only factor of production in the model, private sector employers as wage takers will merely determine how many efficiency units of labor to employ. Let $E_{N S}$ denote the number of efficiency units of labor demanded and therefore employed by the private sector. Accordingly, firms in this sector with production function $g($.$) maximize the following profit function:$

$$
\begin{gathered}
\Pi_{N S}=g\left(E_{N S}\right)-W_{N S} E_{N S} . \\
E_{N S}=E_{N S}^{U}+\beta E_{N S}^{R} .
\end{gathered}
$$

Again, the product price is normalized to 1. $g($.$) is an increasing, concave production$ function, with g'>0, and g'" $<0 . E_{N S}^{U}$ and $E_{N S}^{R}$ denote the total number of workers with urban and rural hukou demanded by firms in the private sector, respectively. In order to obtain closed form solutions analytically, we assume that the production function in the private sector takes the natural $\log$ form with parameter $A$ as follows.

$$
g_{N S}=A \ln \left(E_{N S}\right), A>0 \text {. }
$$

Given this production function, we can get the demand function for labor in the private sector as follows by solving for the profit-maximizing level of employment:

$$
E_{N S}^{*}=\frac{A}{W_{N S}} .
$$

By assumption, all workers located in the urban area who do not get employed in the SOE sector supply their labor to the private sector. The private sector labor market clears for both rural and urban hukou holders, and therefore all labor supplied to that sector is employed. 
The market-clearing conditions in the private sector for workers with each hukou status are specified as follows in equations (14) and (15). $L^{U}$ denotes the total number of urban hukou holders in the economy, and $L_{U}^{R}$ stands for the number of job seekers in the urban area with rural hukou. The superscript refers to the hukou status, and the subscript is the job location.

$$
\begin{aligned}
& L^{U}-E_{S}^{U}=E_{N S}^{U} . \\
& L_{U}^{R}-E_{S}^{R}=E_{N S}^{R} .
\end{aligned}
$$

Since an urban hukou holder provides one efficiency unit of labor for any urban job, the wage for a worker with urban hukou in the private sector is equal to $W_{N S}$. A rural hukou holder is endowed with only $\beta$ efficiency units of labor, and so the wage for a worker with rural hukou in the private sector is equal to $\beta$ times the wage per efficiency unit of labor in the private sector. Hence, the wages for urban and rural hukou holders in the private sector are determined as follows such that the market-clearing conditions in equations (14) and (15) are satisfied, respectively.

$$
\begin{aligned}
& W_{N S}^{U}=W_{N S}^{*} . \\
& W_{N S}^{R}=\beta W_{N S}^{*} .
\end{aligned}
$$

\subsection{Agricultural sector labor market}

As discussed previously, the wage in agricultural sector is invariant with respect to the size of the agricultural sector labor force, and anyone who wishes to enter the agricultural sector can take up self-employment and earn a wage $W_{A}$ regardless of hukou status. Because any person has one efficiency unit of labor for agriculture work, people with different hukou earn the same wage equal to $W_{A}$. 


\subsection{Inter-market linkages}

\subsubsection{Search strategies}

Any worker in this economy has two possible search strategies, either going to the urban area and searching for jobs there or going to the rural area and accepting the agricultural wage. Denote $L_{U}^{U}$ as the number of job seekers in the urban area with urban hukou. The superscript refers to the hukou status, whereas the subscript stands for the geographical location where people are looking for jobs. Similarly, $L_{U}^{R}, L_{R}^{U}$, and $L_{R}^{R}$ follow the same notation, and the two equations below reflect the labor endowment for urban and rural hukou holders, respectively.

$$
\begin{aligned}
& L^{U}=L_{U}^{U}+L_{R}^{U} . \\
& L^{R}=L_{U}^{R}+L_{R}^{R} .
\end{aligned}
$$

\section{(1) Search strategies for workers with urban hukou}

For urban hukou holders, two search strategies are possible. The first strategy is to stay in cities and search for urban jobs, and the second one is go to rural areas and earn the agricultural wage. Denote the probability of a given urban hukou holder being employed in the SOE sector by $P_{S}^{U}$. This probability is endogenous and will be discussed in more detail later. If a person fails to obtain a job in the SOE sector, he or she will immediately go to the private sector and work there. The market-clearing condition in the private sector guarantees that any person who wants to work in the private sector will be able to find a job in this sector. Therefore, the expected wage of the first search strategy for a worker with urban hukou $\mathrm{E}\left(W_{U}^{U}\right)$ satisfies the following equation (20):

$$
\mathrm{E}\left(W_{U}^{U}\right)=W_{S}^{U} P_{S}^{U}+W_{N S}^{U}\left(1-P_{S}^{U}\right) .
$$


Again, the superscript refers to the hukou status, and the subscript stands for the job location. The first term on the right hand side of (20) is the expected wage from the SOE sector, and the second term equals the expected wage from the private sector conditional on failing to get a job in the SOE sector.

Since we assume there is no unemployment in rural areas either, any urban resident who chooses the second search strategy will earn $W_{A}$.

\section{(2) Search strategies for workers with rural hukou}

Similarly, workers with rural hukou also have two search strategies. The first strategy is to migrate to cities and search for urban jobs, and the second is to stay in rural areas and earn the agricultural wage. Denote the probability of a rural migrant becoming employed in the SOE sector by $P_{S}^{R}$. Consequently, the expected wage of the first search strategy for a worker with rural hukou $\mathrm{E}\left(W_{U}^{R}\right)$ consists of two terms, the first term equal to the wage in the SOE sector for a rural hukou holder multiplied by the probability of being hired in the SOE sector for a worker with rural hukou, and the second term equaling the wage in the private sector times the probability of working in this sector. The expected wage associated with migrating to the urban area for a rural hukou holder can thus be described in the following equation.

$$
\mathrm{E}\left(W_{U}^{R}\right)=W_{S}^{R} P_{S}^{R}+W_{N S}^{R}\left(1-P_{S}^{R}\right)
$$

On the other hand, any rural hukou holder who chooses the second search strategy will earn $W_{A}$, so the expected wage of the second strategy is $W_{A}$. 


\section{(3) Probabilities of employment}

We turn our attention now to the probabilities of employment in the SOE sector for workers with different hukou statuses. The probability of a given worker being hired in the SOE sector is calculated as the ratio of jobs in the SOE sector available to this type of worker divided by the number of job seekers with that hukou type in the SOE sector. Specifically, the probability of a worker with urban hukou becoming employed in the SOE sector, $P_{S}^{U}$, is equal to the total number of jobs available to urban hukou holders in the SOE sector divided by job seekers with urban hukou:

$$
P_{S}^{U}=\frac{E_{S}^{U}}{L_{U}^{U}} .
$$

The corresponding probability for workers with rural hukou is calculated in the same way:

$$
P_{S}^{R}=\frac{E_{S}^{R}}{L_{U}^{R}} .
$$

\subsubsection{Expected discretionary income}

Workers allocate themselves among search strategies in order to maximize expected discretionary income by choice of search strategy. As said earlier, the terminology of the expected discretionary income differs from expected wage in that it takes account of other benefits and costs associated with each search strategy. Specifically, the costs of working in the city for rural hukou holders should include both the cost of moving to the city and the cost of living in the city. In fact, the transportation cost of moving to cities is very low in current China, and so we ignore it. Therefore, we refer here only to the cost of living in the city, which is a one dimensional variable measured by its value in monetary terms. In order to capture the big difference in cost of living in the city between workers with rural and urban hukou, without loss of generality, we assume that the cost of being in the city for urban 
hukou holders is equal to zero while $C^{R}$ denotes the extra cost of living in the city for a rural hukou holder. This cost is exogenously determined and the same for all rural hukou holders in the city. ${ }^{2}$

On the other hand, the current hukou system is related to the access to a variety of public service and welfare programs. Let $S^{U}$ and $S^{R}$ denote the values of government-provided benefits associated with urban and rural hukou, respectively, including housing subsidies, social security programs, and so forth. These benefits do not have subscripts because they are not linked to the physical location but are only based on hukou status. In China, the benefits associated with urban hukou are much larger than those associated with rural hukou. That is, $S^{U}>S^{R}$. For analytical convenience, we normalize these benefits so that $S^{R}=0 .^{3}$

Now we can write down the expressions of expected discretionary income associated with each search strategy for workers with different hukou. For an urban hukou holder, the expected discretionary income associated with staying in the urban area is equal to the expected wage plus the government-provided benefits related to urban hukou. Since this benefit will remain the same even if the urban hukou holder migrates to the rural area, the expected discretionary income associated with migrating to the rural area is equal to this benefit plus the expected wage in the rural area. Equations (24) and (25) give us the expressions for these expected discretionary incomes for workers with urban hukou. $D I_{U}^{U}$ and $D I_{R}^{U}$ stand for the discretionary incomes for an urban hukou holder in the urban and rural area, respectively.

\footnotetext{
${ }^{2}$ In reality, this cost can vary among rural hukou holders. For example, workers with children have to bear the education cost, but workers without children need not pay this cost. Indeed, the difference of this cost may partly explain why more young people choose to migrate while older people tend to stay in the rural area. The model developed here can be easily extended to incorporate this feature.

${ }^{3}$ For policy interventions in later sections, a reduction in $C^{R}$ is indeed equivalent to an increase in $S^{R}$. So the reduced cost policy can also be thought as increased benefit policy.
} 


$$
\begin{aligned}
& \mathrm{E}\left(D I_{U}^{U}\right)=\mathrm{E}\left(W_{U}^{U}\right)+S^{U}, \\
& \mathrm{E}\left(D I_{R}^{U}\right)=\mathrm{E}\left(W_{R}^{U}\right)+S^{U} .
\end{aligned}
$$

Similarly, the expected discretionary incomes associated with each search strategy for workers with rural hukou are specified in the following.

$$
\begin{aligned}
& \mathrm{E}\left(D I_{U}^{R}\right)=\mathrm{E}\left(W_{U}^{R}\right)-C^{R}, \\
& \mathrm{E}\left(D I_{R}^{R}\right)=\mathrm{E}\left(W_{R}^{R}\right) .
\end{aligned}
$$

\subsection{Model solutions in equilibrium}

We claim that in equilibrium, rural hukou holders have the same expected discretionary income associated with two search strategies. The reason for this claim is the empirical fact that large numbers of rural hukou holders are working in the city and large numbers stay in rural areas. In other words, some rural hukou holders choose the first search strategy and others choose the second one, so neither strategy is dominant. The equilibrium condition for rural hukou holders is thus characterized by equalization of expected discretionary incomes, as in the following equation:

$$
\mathrm{E}\left(D I_{U}^{R}\right)=\mathrm{E}\left(D I_{R}^{R}\right)
$$

Given that the solution to the equilibrium for rural hukou holders is interior, we can prove that urban hukou holders have a corner solution in the equilibrium in that the expected discretionary income associated with staying in the city is unambiguously larger than that associated with migrating to the rural area. Specifically, we have the following result, the detailed proof of which can be found in Song (2013):

$$
\mathrm{E}\left(D I_{U}^{U}\right)>\mathrm{E}\left(D I_{R}^{U}\right) .
$$


That is, all urban hukou holders choose to stay in the city and take urban jobs. This is quite consistent with the empirical reality that very few urban hukou workers actually choose to move to rural areas due to the availability to better-paying urban jobs (Gagnon et al., 2012). Accordingly, we can derive the following equilibrium results for urban and rural hukou holders, respectively:

$$
\begin{gathered}
L_{R}^{U^{*}}=0 . \\
W_{A}=W_{S}^{R} \frac{E_{S}^{R}}{L_{U}^{R}}+W_{N S}^{R}\left(1-\frac{E_{S}^{R}}{L_{U}^{R}}\right)-C^{R} .
\end{gathered}
$$

The model specified in equations (1) through (31) can be analytically solved. Given the exogenously determined wages in the SOE and rural sector $\left(\bar{W}_{S}^{U}, \bar{W}_{S}^{R}, W_{A}\right)$, labor endowment with each hukou status, and the cost of being in the city for rural migrants $C^{R}$, we can solve the equilibrium employment and wages in different sectors for different hukou holders.

We have solved for some of wages and employment levels. Let us show the solutions to the remaining wages and employment levels to close the model. The solved wages in the private sector for urban and rural hukou holders are presented in equations (32) and (33), and employment levels in the urban private sector and rural agriculture sector are demonstrated in equations (34) to (36), respectively. The values of $E_{N S}^{R^{*}}$ and $L_{U}^{R^{*}}$ in equations (32) through (36) are expressed in equations (37) and (38).

$$
\begin{aligned}
& W_{N S}^{U^{*}}=\frac{A}{L^{U}+\beta L_{U}^{R^{*}}-E_{S}^{*}} . \\
& W_{N S}^{R^{*}}=\beta \frac{A}{L^{U}+\beta L_{U}^{R^{*}}-E_{S}^{*}} .
\end{aligned}
$$




$$
\begin{gathered}
E_{N S}^{U^{*}=} L^{U}-\left(a-\frac{1}{2} \bar{W}_{S}^{U}-\beta \frac{\beta \bar{W}_{S}^{U}-\bar{W}_{S}^{R}}{2 d}\right) . \\
E_{N S}^{R^{*}}=L_{U}^{R^{*}}-\frac{\beta \bar{W}_{S}^{U}-\bar{W}_{S}^{R}}{2 d} . \\
E_{R}^{R^{*}}=L_{R}^{R^{*}}=L^{R}-L_{U}^{R^{*}} . \\
E_{S}^{*}=a-\frac{1}{2} \bar{W}_{S}^{U} .
\end{gathered}
$$

$$
\begin{gathered}
L_{U}^{R^{*}}= \\
\frac{\left[\beta E_{S}^{R^{*}} \bar{W}_{S}^{R}+\beta A-\left(W_{A}+C^{R}\right)\left(L^{U}-E_{S}^{*}\right)\right]+\sqrt{\left[\beta E_{S}^{R^{*}} \bar{W}_{S}^{R}+\beta A-\left(W_{A}+C^{R}\right)\left(L^{U}-E_{S}^{*}\right)\right]^{2}+4 \beta\left(W_{A}+C^{R}\right) E_{S}^{R}\left[\left(L^{U}-E_{S}^{*}\right) \bar{W}_{S}^{R}-\beta A\right]}}{2 \beta\left(W_{A}+C^{R}\right)}
\end{gathered}
$$

The derivations of these solutions are available in an unpublished appendix available from the authors.

\section{Welfare analysis of labor market policies}

This section utilizes the model developed above to conduct several policy experiments to examine how labor market policies that might be carried out by the Chinese government could affect social welfare in China.

Two alternative welfare evaluation criteria are adopted: first-order stochastic dominance approach and abbreviated social welfare function.

The first order welfare dominance approach compares absolute incomes in ranked (ordered) positions in the income distribution and is thus also referred to as "rank dominance”. One distribution X first-order-dominates (FOD) another distribution Y for the class of anonymous, increasing social welfare functions if and only if the income of the person in each rank in $\mathrm{X}$ is at least as great as the income of the person with the 
corresponding rank in $\mathrm{Y}$ and strictly greater someplace. ${ }^{4}$ If the two distributions cross each other, then these two income distributions cannot be ordered using the first-order dominance.

A second welfare approach is the use of an abbreviated social welfare function. According to this approach, social welfare is judged to depend positively on total income and negatively on income inequality and poverty, but the specific social welfare function is otherwise left unspecified. Eventually, for each policy instrument, the overall judgment will be made based on both specified policy evaluation criteria.

All of the welfare analyses we carry out are based on workers' discretionary incomes. Because workers with rural hukou have to bear high costs of living in the city, wages are not all that determine workers' standard of living. Therefore, we use discretionary income (DI) defined as the total income minus the living cost in a given location to reflect workers' standard of living. ${ }^{5}$ Since we have normalized the cost of being in the city for urban hukou holders to zero, the discretionary income for urban hukou holders is the same as their wages in any location. In contrast, the discretionary income for workers with rural hukou working in the urban area are $W_{S}^{R}-C^{R}$, and $W_{N S}^{R}-C^{R}$ in the SOE and private sector, respectively.

The three policies examined in this section are the following:

1. Rural development (RD). Specifically, this policy refers to a rural development program which results in an increase in the agricultural wage (increase $W_{A}$ ).

\footnotetext{
4 “Anonymous” means that all workers are treated identically regardless of which particular ones earn how much
} income. "Increasing” means that social welfare increases whenever one worker's income increase, holding other workers' incomes the same.

${ }^{5}$ In principle, the total income should consist of labor income and government-provided benefits. For simplicity, we assume the benefit for urban hukou holders is normalized to zero, i.e., $S^{U}=0$. That is, the total income only refers to labor income here. The inclusion of benefits will not change the comparison results discussed below, but the gap of discretionary income between urban and rural hukou holders would become even larger. 
2. Reduced Cost (RC). That is, the cost of living in cities for rural hukou holders will be reduced. (reduce $C^{R}$ ), while keeping the cost of living for urban hukou holders constant.

3. Hukou Conversion (HC). This policy means that the government endows a proportion of rural hukou holders working in the city with urban hukou (increase $L^{U}$ ).

The reason we select these three policies is that they are the most discussed and relevant in China's labor policy agenda, but previous studies have not provided satisfactory answers to the welfare consequences of these policies. ${ }^{6}$ There are two major limitations of previous policy analyses (Hertal and Zhai, 2006; Whalley and Zhang, 2007; Ito, 2008). One is that none of the studies above took into account the labor market segmentation between state-owned enterprises and private firms. Second, the policy evaluation criteria were not well defined. Most of previous studies either explicitly or implicitly use the magnitude of rural-to-urban migration as a policy evaluation criterion. They argue that policies which would promote rural-to-urban migration are desirable and welfare-improving. We claim that this criterion is not appropriate because there is no economic or moral reason to simply judge whether migration is good or not for people’s economic welfare in a country.

\subsection{Policy analysis using first-order dominance (FOD)}

In this section, the first-order stochastic dominance method is used to make welfare comparisons between the initial equilibrium and the new equilibrium that would result from each policy change. We use the quantile function to conduct the first-order-dominance comparison. For analytical convenience, from now on, we normalize the total labor force as equal to 1 . Our task is to figure out how many people earn each amount of discretionary income, and compare the two sets of numbers to see whether one set of income distribution lies above the other one. In the initial equilibrium, there are five possible values of discretionary income, which are listed in Table 1. In this table, the group is ordered by the

6 The rural development policy is sometimes called “move jobs to people”, while the reduced cost policy is referred to as "move people to jobs". 
amount of discretionary income from the lowest to the highest. Column 2 explains what type of workers each group refers to, and column 3 shows the five possible values of discretionary income. The last column of Table 1 stands for the number of workers earning the corresponding amount of the discretionary income in column 3.

\section{Table 1 Inserted here}

The ordering for the first three rows comes from the interior equilibrium condition for rural hukou holders. We know that the discretionary income (DI) for group 2 is a weighted average of the discretionary income for group 1 and 3, so this number must lie between the DI for group 1 and 3. Furthermore, since we know that the SOE sector pays a higher wage than the private sector, i.e., $W_{S}^{R}>W_{N S}^{R}$, it follows that DI for group 3 is larger than for group 1 . Since the urban hukou holders don't have to bear the living cost $C^{R}$, their discretionary incomes are equal to the respective wages. By assumption in the model, workers with urban hukou in the SOE sector enjoy the highest DI, $W_{S}^{U}$.

Only one ranking of DI has not been determined as yet, group 3 versus 4 - that is, the discretionary income for rural hukou holders working in the SOE sector $\left(W_{S}^{R}-C^{R}\right)$ versus the DI for urban hukou holders working in the private sector $W_{N S}^{U}$. The model so far cannot determine which of the two values is larger than another. Instead, we need to rely on empirical evidence. As Song (2013) showed based on the RUMIC (Rural-Urban Migration in China) data set, the average monthly wage in the private sector for urban hukou holders is larger than the average wage for rural hukou holders in the SOE sector. Thus, we can infer that $W_{N S}^{U}$ is larger than $W_{S}^{R}$. As a result, the difference between $W_{S}^{R}$ and $C^{R}$ is smaller than $W_{N S}^{U}$, given the fact that the cost of living for rural hukou holders in the city $\left(C^{R}\right)$ is also substantial. Thus, it is safe to assume that $W_{S}^{R}-C^{R}$ is less than $W_{N S}^{U}$. 
The income distribution described above is visualized as the step function in Figure 1. The horizontal axis denotes quantile of labor and the vertical axis denotes the discretionary income for each quantile. The values of discretionary income and employment levels for the five groups of workers in Figure 1 are exactly the same as presented in Table 1.

Figure 1 Inserted Here

The balance of this section presents the results of the three policy interventions using the two welfare criteria described above. The proofs of the results are available in an unpublished appendix available from the authors.

\subsubsection{Rural development (RD): FOD comparison}

For simplicity, we consider the rural development as an increase in the agriculture wage for the policy analysis below. There might be different channels to increase the agriculture wage, such as providing financial loans to rural households, or offering workers with subsidies for better technology. However, the question about which specific channel is better than another is beyond the scope of this study. We assume that the increase in $W_{A}$ is not large enough to alter the ranking of the discretionary income listed in Table 1 . This assumption will also be maintained for the other policy analyses in the subsequent sections.

The effects of the rural development policy on discretionary income and employment levels are summarized in Table 2.

Table 2 Inserted Here

Let us explain the economic intuition behind the results above. As the agricultural wage increases, more rural hukou holders would choose to work in the agricultural sector, and 
therefore fewer people would migrate to the urban area. Since the employment level in the SOE sector for rural hukou holders is independent of the agricultural wage, it remains unchanged. Accordingly, we see more agricultural employment but less employment for rural hukou holders in the private sector.

In addition, the fall in rural-to-urban migration reduces the labor supply to the urban private sector, resulting in a higher market-clearing wage there. This is why the wages would increase in the private sector for both urban and rural hukou holders. Furthermore, the discretionary income moves in the same direction as wages for all groups since there is no change on the cost of living for rural hukou holders in the city. Thus, in Table 2, we observe an increase in discretionary income for three groups: rural hukou holders working in agriculture, rural hukou holders working in the urban private sector, and urban hukou holders working in the private sector.

Given the results in Table 2, we can draw the distribution of discretionary income under the rural development (RD) policy and compare it with the original distribution. Figure 2 depicts the effects of the rural development policy on employment levels and discretionary income for each of the five groups. The solid step function OABCDE stands for the original distribution of discretionary income without the policy. The new income distribution generated by the rural development policy is displayed by dashed lines OA'B'C'D'E'. Comparing the two distributions, they coincide in ranges $\mathrm{BC}$ and $\mathrm{DE}$, and the new distribution lies above the original one in all other ranges. As a result, the new distribution under rural development first-order dominates the original one. Therefore, we conclude that rural development is welfare-improving by the first-order welfare dominance criterion.

Figure 2 Inserted Here 


\subsubsection{Reduced cost (RC): FOD comparison}

A policy of reducing the cost of urban living for rural hukou holders could be implemented by lowering the school fees for migrants' children education or providing housing allowance for the rural migrants working in urban areas. Table 3 presents the results of such a reduced cost policy.

\section{Table 3 Inserted Here}

As the cost-of-living for rural hukou holders in the city decreases, more rural hukou holders would migrate to the city, while fewer people would remain in the rural area and work in the agriculture sector. Since the employment level in the SOE sector for rural hukou holders remains unchanged, the increased labor force in the urban area with rural hukou would enter the private sector. Hence, we see less agricultural employment but more employment for rural hukou holders in the urban private sector.

The reduced cost policy would increase the discretionary income for rural hukou holders in urban areas, whether they are working in the SOE sector or the private sector. However, because of the increased labor supply to the urban private sector, the wages for urban hukou holders in the urban private sector would decrease, so their discretionary income would fall. These effects are summarized in Table 3.

Figure 3 shows the distributions of discretionary income before and after the reduced cost policy. Again, the solid step function corresponds to the original income distribution, and the dashed lines represent the new distribution which would result from the policy of reducing $C^{R}$. As can be seen: (1) Workers in segments $\mathrm{OA}$ and $\mathrm{BC}$ are better off under the policy, (2) Workers in segments A'B' and DE experience no change in discretionary income; and (3) Workers in segments AA' and CD become worse off after the policy experiment. In this way, we can conclude that a policy of reduced cost for urban hukou holders in urban 
areas neither welfare-dominates the original distribution nor is welfare-dominated by it. That is, we cannot make an unambiguous policy evaluation judgment solely based on the first-order dominance criterion.

Figure 3 Inserted Here

\subsubsection{Hukou conversion (HC): FOD comparison}

This policy experiment refers to changing a proportion of rural hukou holders' hukou status from rural to urban hukou. Specifically, the policy instrument analyzed in this section is an incremental increase in $L^{U}$. We conceive of the timing of the policy experiment as follows. At the original equilibrium, the government randomly selects a small percentage of rural hukou holders who are working in the city and immediately grants them urban hukou. After the hukou conversion, workers and firms will re-optimize and reach a new equilibrium. The effects of such a hukou conversion policy are shown in Table 4.

\section{Table 4 Inserted Here}

Due to the hukou conversion policy, people whose hukou types get converted would be better off and earn higher discretionary income. However, the hukou conversion policy would increase the supply of labor to the urban private sector, causing the wage there to fall. This results in a decrease in the discretionary income for people in the private sector with either hukou type.

Given the results above, we draw the distribution of discretionary income under the hukou conversion policy, which is shown in Figure 4.

Figure 4 Inserted Here 
Compared to the original income distribution, workers in segments AA', B'B, and C'C become better off. However, workers in segments OA' and CD become worse off. Other segments remain unchanged. As a consequence, the post-policy distribution neither first-order welfare dominates the original one nor is dominated by it.

In summary, only the rural development policy yields an unambiguously welfare-improving income distribution using the first-order welfare dominance criterion. In contrast, the reduced cost and hukou conversion policies have ambiguous effects on social welfare using the first-order dominance criterion. Finally, no proposed policy among the three alternatives is unambiguously welfare-decreasing using this welfare criterion.

\subsection{Policy analysis using the abbreviated social welfare function approach}

The terminology of abbreviated social welfare function was due to Lambert (1993) and employed by Fields (2005) in the context of the simplified Harris-Todaro model. In the analysis below, we work with a class of abbreviated social welfare functions of the form:

$\mathrm{SW}=f$ (Total income, poverty, income inequality), $f_{1}>0, f_{2}<0, f_{3}<0$.

Again, "income" in this context refers to the discretionary income defined as previously. In this abbreviated social welfare function, economic well-being depends positively on the total income earned by all workers, negatively on poverty, and negatively on income inequality. Since there are five values of income throughout this economy, the total income of all workers is the sum of discretionary income earned by each group. The income of each group is the product of income per worker times the number of workers in each group.

The second component in the specified welfare function is poverty. Specifically, poverty is measured here by the poverty headcount or poverty headcount ratio. Because the total 
population is constant, the results of the analysis based on the two measures are the same. Hence, we measure poverty by the poverty headcount defined as the number of workers whose discretionary incomes are below or equal to a given poverty line. As we know, most agriculture workers in China still earn very little and have low standard of living. Hence, a reasonable place to set the poverty line in the model is the agricultural wage in the original equilibrium, that is, $W_{A}$. We set the poverty line $\mathrm{z}=W_{A} \cdot{ }^{7}$ Accordingly, there are two groups of workers in poverty, including agricultural workers in rural China and workers with rural hukou working in the urban private sector.

In terms of measuring income inequality, we use the difference in average discretionary income between workers living in the urban and rural area as the measure of inequality. One of the biggest policy concerns on inequality in current China is urban-rural inequality, that is, the income gap between urban and rural dwellers. ${ }^{8}$ The average income for rural dwellers is equal to $W_{A}$, since all workers in the rural area earn this amount. The average income for people living in the urban area is a weighted average of four groups of workers in the city.

Above, we defined each of the arguments of the abbreviated social welfare function. Combining these, we obtain the results shown in Table 5. Again, the proofs of these results are available in an unpublished appendix available from the authors.

Table 5 Inserted here

As can be seen, only the rural development policy is unambiguously welfare-improving using the abbreviated social welfare function, in that it increases total income, reduces income

\footnotetext{
${ }^{7}$ If the poverty line is set at the new agriculture wage after the rural development policy, then the rural development policy would not reduce poverty using the poverty headcount measure, but would reduce the depth of poverty. This would require us to use more complicated poverty measures such as $\mathrm{P}_{2}$. For reasons of mathematical tractability and to be able to use the poverty headcount measure, we set the poverty line equal to the original agriculture wage before any policy change.

8 To ease the calculations, we found it easier to use the difference in discretionary income of urban workers compared to rural workers rather than the ratio.
} 
inequality, and also reduces poverty. The reduced cost policy does reduce inequality, but it would also make the total income fall, rendering the consequence welfare-ambiguous. The hukou conversion policy also generates a welfare-ambiguous result in that it has ambiguous effects on total income and income inequality depending on parameter values.

The welfare economic results based on the first-order-dominance approach and the abbreviated social welfare function are summarized in columns 2 and 3, respectively, of Table 6.

\section{Table 6 Inserted Here}

According to the results presented above, the rural development policy would increase social welfare, while the reduced cost and hukou conversion policies would have ambiguous effects on social welfare no matter which of the two welfare evaluation criteria we use. In addition, none of the proposed policies is unambiguously welfare-decreasing.

\section{Concluding remarks}

Based on the central features of the current Chinese labor market, the present paper constructed a three-sector segmented labor market model including an urban SOE (state-owned enterprises) sector, an urban private sector, and a rural agricultural sector. These sectors' labor markets differ from one another in terms of the way each one operates, the way employment and wages are determined within each, how the several labor markets connect with one another, and how conditions in the various sectors differ as between workers with urban and rural residential permits.

The system of residential permits, unique to China, has been called by its Chinese name hukou. The model presented in this paper shows that the hukou system affects the current Chinese labor market through two major channels. One is that the urban state-owned enterprises (SOEs) practice both hiring discrimination and wage discrimination against rural 
hukou holders. Another feature of the hukou system is that rural hukou holders have to bear a large cost when they live in the city, but they do not have the same access to various government programs and public services as urban hukou holders. These two mechanisms together help explain a puzzle observed in current China: a considerable number of rural hukou holders still choose to stay in the poor rural area and earn very little, instead of migrating to urban areas where labor shortages are endemic and wages are many times higher.

Based on the newly-developed theoretical model, this paper then conducted a careful welfare economic analysis of three labor market policies - including promoting rural development, reducing the cost of living for rural hukou holders in the city, and converting some rural migrants' hukou status from rural to urban - which are among the most discussed and relevant policies in the current Chinese labor market policy agenda. The effects of these policies were analyzed using two alternative policy evaluation criteria: first-order stochastic dominance and the abbreviated social welfare function approach

Overall, the results showed that the rural development policy is the only policy which unambiguously increases social welfare using either of these social welfare criteria. By contrast, the reduced cost policy and the hukou conversion policy have ambiguous effects on social welfare using either welfare criterion. None of the three policies was shown to be unambiguously welfare-reducing.

Looking ahead, the model might be carried forward in a number of directions. One is to build in additional features. These might include: allowing for rural non-agricultural employment in township and village enterprises (TVEs), which exist in large numbers in rural China but are not yet in the model; extending the model to have a number of distinct urban and rural areas rather than just one of each; and introducing on-the-job search in addition to searching for high-wage jobs by migrating to (or remaining in) the high-wage locations. Another is to analyze other policies. One possibility is to provide rural hukou 
holders with more education and training (increase $\beta$ ) and to test its welfare consequences. In addition, it would also be interesting to examine the labor market outcomes and welfare consequences of removing labor market discrimination in state-owned enterprises in urban China. And a third possible future direction could be to conduct a policy analysis in which the amount of a development budget is fixed and therefore making explicit both the benefits and the costs of using limited resources in one way rather than another.

This paper will have succeeded if it has contributed to the formulation of better analytical methods and more sound policy dialogue concerning the Chinese labor market. 


\section{References}

Ash, Robert. 2010. "The Chinese Economy after 30 Years of Reform: Perspectives from the Agricultural Sector.” Journal of Asian Studies 28 (1): 36-62.

Becker, Gary S. 1971. The Economics of Discrimination, 2nd ed. Chicago: University of Chicago.

Cai, Fang. 2010. "Demographic Transition, Demographic Dividend, and Lewis Turning Point in China.” China Economic Journal 3 (2): 107-119.

Chan, Kam Wing. 2010. "The Household Registration System and Migrant Labor in China: Notes on a Debate.” Population and Development Review 36 (2): 357-364.

Chen, Guibao, and Jin Yang. 2010. “Access to Compulsory Education by Rural Migrants' Children in Urban China: A Case Study from Nine Cities.” Educational Research 1 (10): 512-519.

Chen, Yi, Sylvie Demurger, and Martin Fournier. 2005. “Earnings Differentials and Ownership Structure in Chinese Enterprises.” Economic Development and Cultural Change 53 (4): 933-958.

Dong, Xiao-yuan, and Lixin Colin Xu. 2009. “Labor Restructuring in China: Toward a Functioning Labor Market.” Journal of Comparative Economics 37(2): 287-305.

Feng, Shuyi. 2008. "Land Rental, Off-farm Employment and Technical Efficiency of Farm Households in Jiangxi Province, China.” NJAS-Wageningen Journal of Life Sciences 55 (4): 363-378.

Fields, Gary S. 2007. "Labor Market Policy in Developing Countries: A Selective Review of the Literature and Needs for the Future.” International Policy Center Working Paper Series 32.

Fields, Gary S. 2005. “A Welfare Economic Analysis of Labor Market Policies in the Harris-Todaro Model.” Journal of Development Economics 76 (1): 127-146.

Fields, Gary S. 1975. "Rural-Urban Migration, Urban Unemployment and Underemployment and Job Search Activity in LDC’’”. Journal of Development Economics 2 (2): 165-188.

Gagnon, Jason J., Theodora Xenogiani, and Chunbing Xing. 2012. “Are All Migrants Really Worse Off in Urban Labour Markets: New Empirical Evidence from China.” IZA Discussion Paper 6268.

Giulietti, Corrado, Guangjie Ning, and Klaus F. Zimmermann. 2012. "Self-employment of Rural-to-urban Migrants in China.” International Journal of Manpower 33 (1): 96 -117.

Harris, John, and Michael Todaro. 1970. "Migration, Unemployment, and Development: A Two Sector Analysis.” American Economic Review 60 (1): 126-142. 
Hellerstein, Judith K., David Neumark, and Kenneth Troske. 2002. "Market Forces and Sex Discrimination.” Journal of Human Resources 37 (2): 353-380.

Hertel, Thomas, and Fan Zhai. 2006. "Labor Market Distortions, Rural-urban Inequality and the Opening of China’s Economy.” Economic Modelling 23 (1): 76-109.

Ito, Junichi. 2008. “The Removal of Institutional Impediments to Migration and Its Impact on Employment, Production and Income Distribution in China.” Economic Change and Restructuring 41 (3): 239-265.

Knight, John, Deng Quheng, and Li Shi. 2011. “The Puzzle of Migrant Labor Shortage and Rural Labor Surplus in China.” China Economic Review 22 (4): 585-600.

Lambert, Peter J. 1993. The Distribution and Redistribution of Income: A Mathematical Analysis. Oxford: Blackwell.

Lewis, W. Arthur. 1954. "Economic Development with Unlimited Supplies of Labour.” Manchester School 22: 139-191.

Lu, Ming, and Shiqing Jiang. "Labor Market Reform, Income Inequality and Economic Growth in China.” China \&World Economy 16(6): 63 - 80.

Meng, Xin. 2000. Labour Market Reform in China. Cambridge: Cambridge University Press.

Neurnark, David. 1988. “Employers' Discriminatory Behavior and the Estimation of Wage Discrimination.” Journal of Human Resources 23 (3): 279-95.

Prieto-Rodriguez, Juan, Juan Gabriel Rodriguez, and Rafael Salas. 2008. “A Theoretical Model of Wage Discrimination with Inspection Fines.” Economics Bulletin 10 (3): 1-9.

Razin, Assaf, and Efraim Sadka. 1995. "Resisting Migration: Wage Rigidity and Income Distribution.” American Economic Review 85 (2): 312-316.

Saint-Paul, Gilles. 1994. “Unemployment, Wage Rigidity and Returns to Education.” European Economic Review 38 (3): 535-543.

Song, Jin, Shi Li. 2010. “Ownership and Earnings Inequality in Urban China.” Frontiers of Economics in China 5(4): 582-603.

Song, Ligang, and Yongsheng Zhang. 2010. "Will Chinese Growth Slow after the Lewis Turning Point?” China Economic Journal 3 (2): 209-219.

Song, Yang. 2013. “Essays on the Chinese Labor Market.” PhD dissertation, Cornell University. 
Song, Yang. 2012. "Poverty Reduction in China: The Contribution of Popularizing Primary Education.” China \& World Economy 20 (1): 105-122.

Stiglitz, Joseph E. 1982. “The Structure of Labor Markets and Shadow Prices in L.D.C.’s.” In Migration and the Labor Market in Developing Countries, edited by Richard H. Sabot, 13-63. Boulder: Westview Press.

Whalley, John, and Shunming Zhang. 2007. “A Numerical Simulation Analysis of Labor Mobility Restrictions in China.” Journal of Development Economics 83 (2): 392-410. 


\section{Tables}

Table 1 The Initial Distribution of Discretionary Income (DI)

\begin{tabular}{cccc}
\hline Group & Group Description & $\begin{array}{c}\text { DI (lowest to } \\
\text { highest) }\end{array}$ & $\begin{array}{c}\text { Number of people } \\
\text { earning each DI }\end{array}$ \\
\hline 1 & $\begin{array}{c}\text { Rural hukou holders working in } \\
\text { the private sector }\end{array}$ & $W_{N S}^{R}-C^{R}$ & $E_{N S}^{R}$ \\
2 & $\begin{array}{c}\text { Rural hukou holders working in } \\
\text { agriculture sector }\end{array}$ & $W_{A}^{R}$ & $E_{S}^{R}$ \\
3 & $\begin{array}{c}\text { Rural hukou holders working in } \\
\text { the SOE sector }\end{array}$ & $W_{S}^{R}-C^{R}$ & $E_{N S}^{U}$ \\
4 & $\begin{array}{c}\text { Urban hukou holders working } \\
\text { in the private sector }\end{array}$ & $W_{N S}^{U}$ & $E_{S}^{U}$ \\
\hline & $\begin{array}{c}\text { Urban hukou holders working } \\
\text { in the SOE sector }\end{array}$ & $W_{S}^{U}$ & \\
\hline
\end{tabular}

Note: "NS" sector denotes the private sector (non-state-owned enterprises), while "S" sector denotes the state-owned enterprises. The superscript denotes the hukou type, and the subscript refers to the economic sector.

Table 2 The Effects of Rural Development Policy

\begin{tabular}{ccccc}
\hline Group & Group Description & Employment & Wages & DI \\
\hline 1 & $\begin{array}{c}\text { Rural hukou holders working } \\
\text { in the private sector } \\
\text { Rural hukou holders working } \\
\text { in agriculture sector }\end{array}$ & + & + & + \\
3 & $\begin{array}{c}\text { Rural hukou holders working } \\
\text { in the SOE sector }\end{array}$ & 0 & 0 & 0 \\
$\quad \begin{array}{l}\text { Urban hukou holders } \\
\text { working in the private sector } \\
4\end{array}$ & 0 & + & + \\
5 & $\begin{array}{l}\text { Urban hukou holders } \\
\text { working in the SOE sector }\end{array}$ & 0 & 0 & 0
\end{tabular}

Note: “+” denotes an increase in a particular variable, “-” denotes a decrease, and "0" stands for no change. 
Table 3 The Effects of Reduced Cost Policy

\begin{tabular}{|c|c|c|c|c|}
\hline Group & Group Description & Employment & Wages & DI \\
\hline 1 & $\begin{array}{l}\text { Rural hukou holders working } \\
\text { in the private sector }\end{array}$ & + & - & + \\
\hline 2 & $\begin{array}{l}\text { Rural hukou holders working } \\
\text { in agriculture sector }\end{array}$ & - & 0 & 0 \\
\hline 3 & $\begin{array}{l}\text { Rural hukou holders working } \\
\text { in the SOE sector }\end{array}$ & 0 & 0 & + \\
\hline 4 & $\begin{array}{l}\text { Urban hukou holders } \\
\text { working in the private sector }\end{array}$ & 0 & - & - \\
\hline 5 & $\begin{array}{l}\text { Urban hukou holders } \\
\text { working in the SOE sector }\end{array}$ & 0 & 0 & 0 \\
\hline
\end{tabular}

Note: “+” denotes an increase in a particular variable, “-” denotes a decrease, and “0” stands for no change.

Table 4 The Effects of Hukou Conversion Policy

\begin{tabular}{|c|c|c|c|c|}
\hline Group & Group Description & Employment & Wages & DI \\
\hline 1 & $\begin{array}{l}\text { Rural hukou holders working } \\
\text { in the private sector }\end{array}$ & - & - & - \\
\hline 2 & $\begin{array}{l}\text { Rural hukou holders working } \\
\text { in agriculture sector }\end{array}$ & - & 0 & 0 \\
\hline 3 & $\begin{array}{l}\text { Rural hukou holders working } \\
\text { in the SOE sector }\end{array}$ & 0 & 0 & 0 \\
\hline 4 & $\begin{array}{l}\text { Urban hukou holders } \\
\text { working in the private sector }\end{array}$ & + & - & - \\
\hline 5 & $\begin{array}{c}\text { Urban hukou holders } \\
\text { working in the SOE sector }\end{array}$ & 0 & 0 & 0 \\
\hline
\end{tabular}

Note: “+” denotes an increase in a particular variable, “_” denotes a decrease, and "0” stands for no change. 


\section{Table 5 Welfare Analysis Using Abbreviated Social Welfare Function}

\begin{tabular}{ccccc}
\hline $\begin{array}{c}\text { Labor market } \\
\text { policy }\end{array}$ & $\begin{array}{c}\text { Change in } \\
\text { total income }\end{array}$ & $\begin{array}{c}\text { Change in } \\
\text { poverty } \\
\text { headcount }\end{array}$ & $\begin{array}{c}\text { Change in } \\
\text { income } \\
\text { inequality }\end{array}$ & $\begin{array}{c}\text { Change in } \\
\text { welfare }\end{array}$ \\
$\begin{array}{c}\text { Rural } \\
\text { Development }\end{array}$ & + & - & - & + \\
$\begin{array}{c}\text { Reduced } \\
\text { Cost }\end{array}$ & - & 0 & - & ambiguous \\
& & & & \\
Hukou & ambiguous & - & ambiguous & ambiguous \\
Conversion & & & &
\end{tabular}

Note: “+” denotes an increase in a particular variable, “-” denotes a decrease, and "0" stands for no change.

Table 6 Summary of Welfare Economic Analysis of the Three Policies

\begin{tabular}{ccc} 
Labor market policy & $\begin{array}{c}\text { Change in social welfare } \\
\text { using first-order } \\
\text { dominance }\end{array}$ & $\begin{array}{c}\text { Change in social welfare } \\
\text { using abbreviated social } \\
\text { welfare function }\end{array}$ \\
Rural Development & + & + \\
Reduced Cost & Ambiguous & Ambiguous \\
Hukou Conversion & Ambiguous & Ambiguous \\
\hline
\end{tabular}

Note: “+” denotes an increase in social welfare. 


\section{Figures}

Figure 1 Initial Quantile Distribution of Discretionary Income (DI)

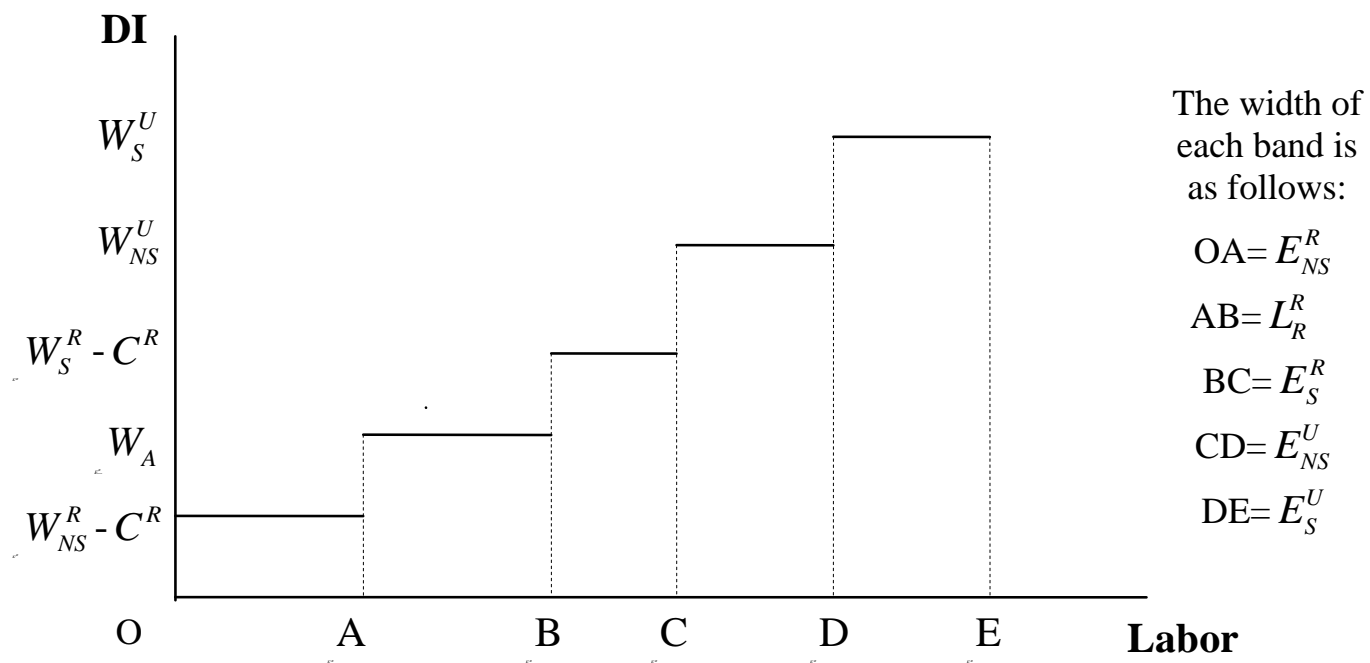

Figure 2 Quantile Distribution under Rural Development

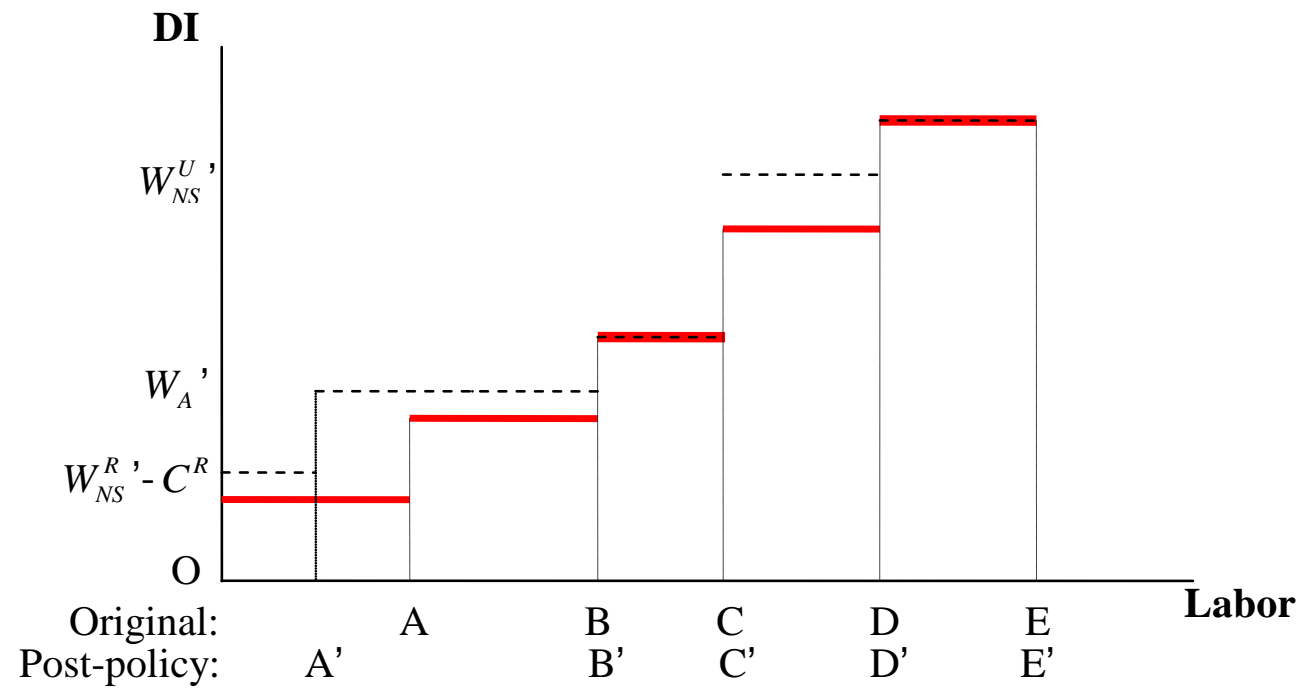


Figure 3 Quantile Distribution under Reduced Cost

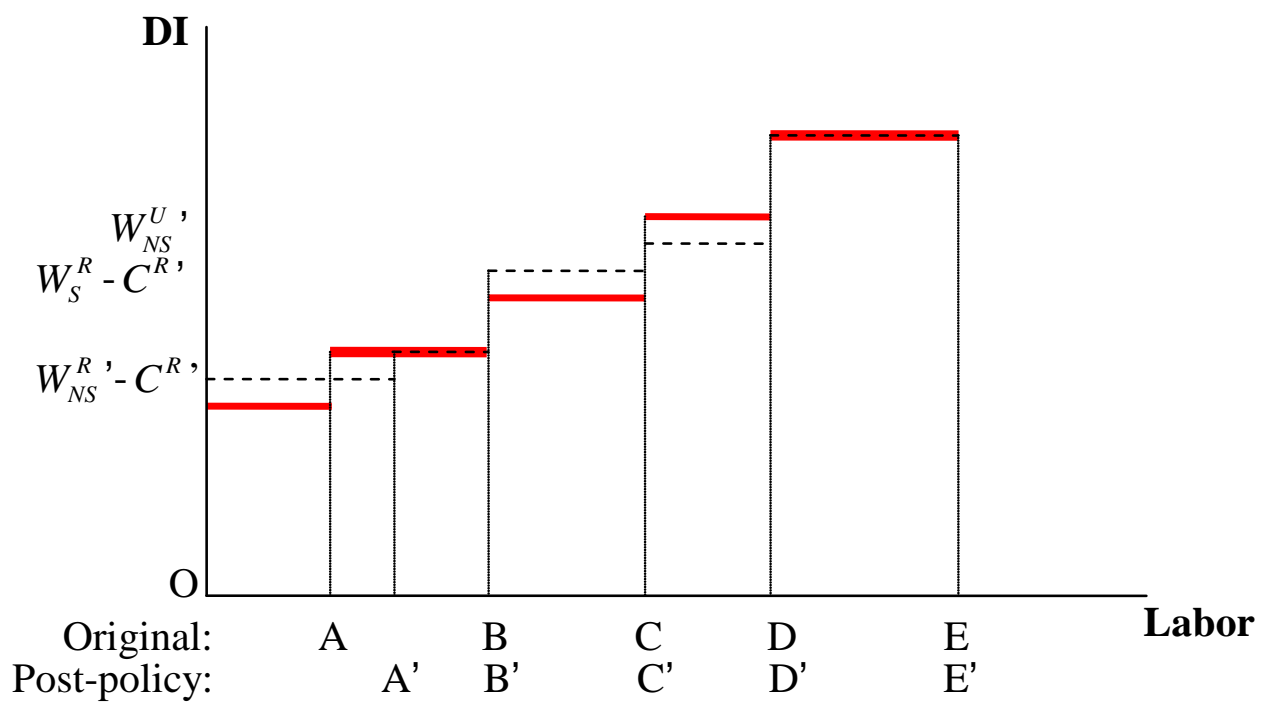

Figure 4 Quantile Distribution under Hukou Conversion

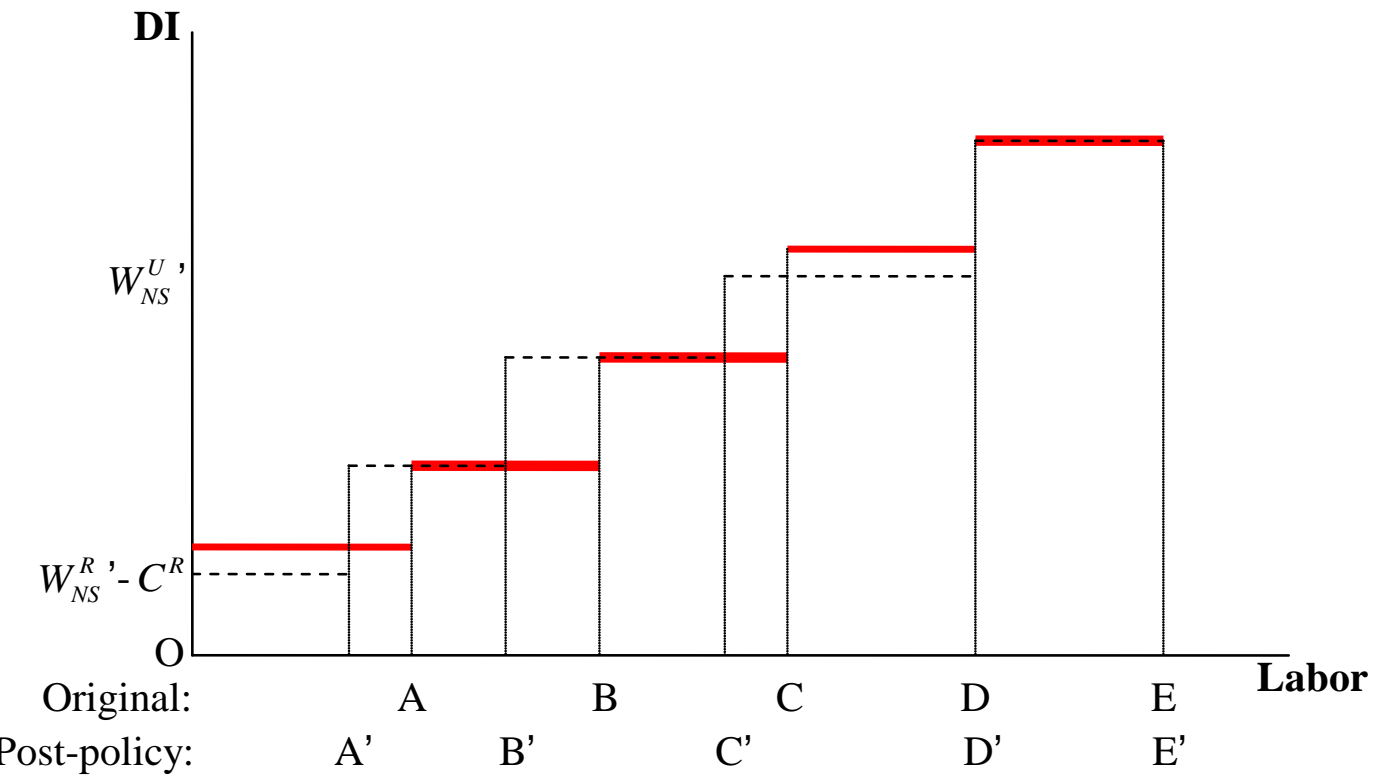

